\title{
Metacognition, achievement goals, study strategies and academic achievement: pathways to achievement
}

\author{
Anneke Vrugt • Frans J. Oort
}

Received: 25 August 2007 / Accepted: 13 May 2008/

Published online: 12 June 2008

(C) The Author(s) 2008

\begin{abstract}
The purpose of this research was to develop and test a model of effective selfregulated learning. Based on effort expenditure we discerned effective self-regulators and less effective self-regulators. The model comprised achievement goals (mastery, performance-approach and -avoidance goals), metacognition (metacognitive knowledge, regulation and experience), study strategies (metacognitive, deep cognitive, surface cognitive and resource management strategies) and academic achievement. The relationships in the model were tested with controlling for intellectual ability, gender and age. The results showed that effective self-regulated learning involved two pathways: a metacognitive and a strategy pathway. The first pathway involved a positive relationship of mastery goals and a negative relationship of performance-avoidance goals with metacognition. Metacognition positively affected the use of the four study strategies. The strategy pathway involved positive effects of mastery and performance-approach goals on the use of metacognitive and deep cognitive strategies. Further, performance-approach goals positively affected the use of surface cognitive and resource management strategies. The use of metacognitive and resource management strategies had a positive and the use of surface cognitive strategies had a negative effect on exam scores.
\end{abstract}

Keywords Metacognition - Achievement goals · Study strategies · Academic achievement . Self-regulated learning

Self-regulation is an important aspect of student learning in academic performance. According to Wolters (2003) 'Self-regulated learners are autonomous, reflective and efficient learners, and have the cognitive and metacognitive abilities as well as the motivational beliefs and attitudes needed to understand, monitor and direct their own learning (p. 189). Wolters has described self-regulated learners as actively engaged in the learning process. Most self-regulated learning models assume that learners are actively

\footnotetext{
A. Vrugt $(\bowtie) \cdot$ F. J. Oort

Faculty of Social and Behavioural Sciences, University of Amsterdam, Roetersstraat 15, 1018 WB Amsterdam, The Netherlands

e-mail: a.j.vrugt@uva.nl
} 
engaged in the learning process (Boekaerts and Corno 2005; Winne 1996; Zimmerman 2000). Self-regulated learners are thought to hold the belief that effort leads to success, which drives their willingness to make a commitment to effort utilization and persistence in academic tasks (Ames 1992; Weiner 1986; Wolters 2003; Zimmerman and Martinez-Pons 1990). Ames (1992) and Covington $(1983,1985)$ pointed out that the willingness to make a commitment to effort utilization is necessary for the development of the relevant skills, strategies and academic performance. In line with this, several recent studies reported a positive effect of effort investment on academic achievement (Dupeyrat and Martiné 2005; Elliot et al. 1999; McKenzie et al. 2004; Wolters 2004). Based on these considerations, it was assumed that high effort expenditure is characteristic of effective self-regulated learners and that high effort expenditure results in high achievement.

Winne (1996) noted that students who do not receive much explicit instructions about the knowledge and skills that underlie self-regulated learning, nonetheless are developing forms of self-regulated learning and may develop forms of self-regulated learning that are suboptimal. Thus, it is plausible that there are qualitative and quantitative differences between the self-regulatory processes of effective and less effective self-regulated learners. Theorists, such as Boekaerts (1997), Pressley (1995) and Winne (2005), have pointed out that it is important to investigate in what respects effective and less-effective self-regulatory students differ. Understanding how learners use self-regulated learning may provide clearer guidances about how to engineer the scaffolds for supporting the development of effective self-regulated learning.

The major models of self-regulated learning differ in their specific perspectives on selfregulation and employ different terminologies (e.g. Boekaerts 1997; Pintrich 2004; Schunk 2001; Winne 2001; Zimmerman and Schunk 2001). However, there is consensus among theorists that self-regulated learning involves goal setting, metacognition and the use of (meta)cognitive strategies.

We tested the predictions of a model that explains the impact of achievement goals on metacognition and on study strategies, of metacognition on study strategies and of study strategies on academic achievement. We used path analysis to determine the relative strength of the relationships between the relevant variables for effective and less effective self-regulated learners. Such causal modeling procedures enable the testing of complex conceptual models as a whole and go beyond the mere examination of relationships between two sets of variables. The conceptual foundation of the model for effective selfregulators tested in this study is a synthesis of previous work. We first review the previous work and than present the model that guided our research.

\section{Achievement goals}

A general assumption that most models of self-regulated learning share is that there is some type of goal, criterion, or standard against which to assess the operation of the learning process and that guides regulatory processes (Boekaerts and Corno 2005; Winne 1996; Zimmerman 2000). It is assumed that learners set standards or goals to strive for in their learning, monitor their progress toward these goals, and then adapt and regulate their cognition, motivation and behavior in order to reach these goals (Pintrich 2000). Goal setting takes place in the first phase of the self-regulatory process (e.g. Pintrich 2004; Zimmerman and Kitsantas 2005).

Achievement goal theory describes general goal orientations that concern the reasons or purposes students are pursuing when approaching and engaging in a task. This theory 
originally stressed two general orientations to achievement: mastery and performance goals (Ames 1992; Dweck and Leggett 1998). Mastery goals orient the student towards learning and understanding, developing new skills, and a focus on self-improvement using self-referenced standards. Performance goals represent a concern with demonstrating ability, obtaining recognition of high ability, protecting self-worth and a focus on comparative standards relative to others and attempting to surpass others (Pintrich 2000). With performance goals opposite motives are involved, namely, the aim at a positive evaluation and the avoidance of a negative one. Because of these opposite motives, different authors (e.g., Elliot 1997; Elliot and Church 1997) have proposed a framework in which the performance goal construct is bifurcated into approach and avoidance forms of regulation. A performance-approach goal orients the student towards achieving higher levels than others and demonstrating high ability. With a performance-avoidance goal the student is concerned with avoidance of the demonstration of low ability or appearing stupid.

In a review of the achievement goal literature, Ames (1992) noted considerable benefits of pursuing mastery goals over performance goals. The assumption that mastery goals are more adaptive than performance goals is referred to as a mastery goal perspective, because it implies that students are best off exclusively focusing on mastery in their achievement pursuits. More recently, Barron and Harackiewicz (2001) evidenced that maladaptive learning patterns were mainly associated with performance-avoidance goals and active learning behaviors with performance-approach goals. Therefore, a number of theorists argued for a multiple goal perspective in which both mastery and performance-approach goals can be beneficial (e.g. Barron and Harackiewicz 2001; Harackiewicz et al. 2002). In support of the multiple goal perspective, Dupeyrat and Martiné (2005), Elliot et al. (1999) Harackiewicz et al. (1998), and Wolters (2004) found a positive relationship between mastery and performance-approach goals. Further the results of Elliot and Church (1997), Elliot et al. (1999), Midgley et al. (1998), and Wolters (2004) showed that performanceapproach and -avoidance goals were positively related.

Based on Markus and Ruvolo's theory on possible selves (1989), we assumed that performance-avoidance goals also can have some beneficial effects. According to Markus and Ruvolo (1989) goals affect performance because goals form a bridge between a student's present state and his or her future state. The mental representations a student has of him- or herself concerning the approach and attainment of a goal are called 'possible selves'. Such a possible self can take positive guises if it concerns a student's hopes and desires. It also may take negative guises if topics that inspire fear are involved, such as incompetence and failure. Goals optimally contributes to a student's motivation if they not only activate a positive desired possible self but also a negative feared possible self which represents what might happen when the desired state is not reached. If this negative possible self is less prominent than a positive possible self, and the student knows what to do to avoid the feared state, it may have a motivating effect (Oyserman and Markus 1990). Thus, when a weak performance-avoidance goal, representing a weak negative feared possible self, would be related to a strong mastery goal, the weak performanceavoidance goal may have a positive effect on the planning and monitoring of effective self-regulators. The results of Suárez Reveiro et al. (2001) demonstrated that one of the characteristics of effective self-regulators was their desire to avoid being judged negatively by others.

Suárez Reveiro et al. (2001) pointed out that students' adoption of different goals allow them to manage their learning and make it more flexible, so that they are able to attune their behavior optimally to the task and achieve good results. Thus, the study of effective self- 
regulation should involve a multiple goal perspective, assuming that students simultaneously pursue mastery, performance-approach and -avoidance goals.

\section{Metacognition}

The literature in the area of metacognition identifies two distinct aspects of metacognition: knowledge about cognition and the regulation of cognition (Brown 1987; Flavell 1979; Veenman et al. 2006). Knowledge about cognition refers to the knowledge or beliefs about what factors or variables interact in what ways to affect the course and outcomes of cognitive enterprises (Flavell 1979). Flavell and Wellman (1977) distinguished metacognitive knowledge concerning the person (e.g. 'I am good at memorizing'), the task (e.g. 'The study book for Introduction to Psychology is easier than that for statistics.') and the strategy (e.g. 'Elaboration helps to understand.') and knowledge about the interaction between these three variables (e.g. 'Rehearsal helps me when I have to memorize something, but when I have to understand other strategies like organizing the study material are more helpful.'). Cross and Paris (1988) discerned three kinds of metacognitive knowledge: declarative knowledge (knowing what factors influence human cognition), procedural knowledge (knowing how certain skills work and how they should be applied), and conditional knowledge (knowing when strategies are needed).

Regulation of cognition refers to a set of activities that help students control their learning. Although a number of regulatory skills have been described in the literature, three essential skills are included in all accounts: planning, monitoring and evaluation (Jacobs and Paris 1987; Veenman et al. 2006; Winne 1996). Planning involves the selection of appropriate strategies and the allocation of resources that affect performance. Monitoring refers to one's on-line awareness of comprehension and task performance. Evaluation refers to appraising the products and efficiency of one's learning, such as re-evaluating one's goals and conclusions.

A component of metacognition that has received relatively little attention concerns metacognitive experiences. Flavell (1979) describes metacognitive experiences as 'any conscious cognitive or affective experience that accompanies and pertains to any intellectual enterprise.' Efklides and Petkaki (2002) noted that persons who engage in cognitive tasks experience various affects, such as interest, and form judgments regarding their task processing and how well they are doing. These feelings and judgments regarding the learning achieved are metacognitive in nature because they monitor features of the cognitive processing of the task at hand and the person's response to it. The Awareness of Independent Learning Inventory (AILI; Elshout-Mohr 1992; Elshout-Mohr et al. 2004; Meijer et al. 2003; Meijer et al. 2006) assesses not only metacognitive knowledge and regulation, but also metacognitive experiences.

One key assumption of all theories of metacognition is that knowledge and regulation of cognition are mutually correlated (e.g. Jacobs and Paris 1987; Flavell 1979). However, this positive relationship does not occur when metacognitive knowledge is incorrect, since incorrect metacognitive knowledge about their learning processes prevents students from amending this knowledge (Veenman et al. 2006).

The Metacognitive Awareness Inventory (MAI) of Schraw and Dennison (1994) showed that knowledge of cognition and regulation of cognition were strongly intercorrelated. This was confirmed by the results of Sperling et al. (2004). The results of Meijer et al. (2003, 2006) show that knowledge of cognition, regulation of cognition and experience of 
cognition as measured by AILI also have strong positive relationships. Hence, in the present study the total AILI scores were used.

\section{Metacognition, achievement goals and strategy use}

Few data are available concerning the relationships of achievement goals and the engagement in metacognitive activities. Schraw et al. (1995) found that students who strongly adopt mastery goals reported more metacognitive knowledge than students with less strong mastery goals. Ford et al. (1998) reported that a learning orientation predicted metacognitive regulation. In contrast, Sperling et al. (2004) reported that intrinsic motivation was not related to the engagement in metacognitive activities.

Achievement goal literature is concerned with why a student is pursuing a task and how the orientation to the task can influence many of the different processes of self-regulation (Pintrich 2000). When students pursue mastery goals they are motivated to master and learn the material. They are focused on the task and ask themselves: 'How can I understand this?' or 'How can I do this?' With mastery goals students actively search their memory for relevant prior knowledge, such as content knowledge and metacognitive knowledge about the task and strategies, relevant for mastering the material. Moreover, they orient their regulatory processes to cues that provide information about their progress in learning. Thus, the pursuit of a mastery goal evokes engagement in metacognitive activities (e.g. Ames 1992; Boekaerts 1997).

A performance-approach goal orients the student toward normative comparison and demonstrating high ability. Schraw et al. (1995) found that performance-approach goals were not related to metacognitive knowledge. Furthermore, the results of Sperling et al. (2004) showed that extrinsic goals were unrelated to the engagement in metacognitive activities. With performance-approach goals learning itself is viewed as a way to achieve a desired goal and attention is directed toward achieving normatively defined success. Thus, it seems reasonable to assume that concerns about performance evaluation do not promote the engagement in metacognitive activities relevant for the task performance.

Performance-avoidance goals focus students on the possibility of a negative outcome and appearing stupid, which might engender threat appraisals and anxiety. However, we argued before that the pursuit of a weak performance-avoidance goal, representing a weak negative feared possible self, could have a positive effect on the planning and monitoring. In accordance with this, we assumed that approach-avoidance goals would have a negative relationship with the engagement in metacognitive activities.

Sperling et al. (2004) and Luwel et al. (2003) pointed out that metacognitive knowledge and regulation influence decisions which strategy to use. Luwel et al. (2003) administered interviews to gather data about six grader's metacognitive knowledge and regulation. In the study of Sperling et al. (2004) first-year students completed the MAI. Both studies found that the engagement in metacognitive activities was positively related to the use of all relevant strategies. Decisions on strategy use imply that the strategy is adapted to the task and to the stage of the task performance. In different stages of the task performance different strategies may be appropriate. For example, a student may initially use memorization strategies, recognizes that memorization is not working, and than decides to outline and answer adjunct questions or vice versa (Olausen and Bräten 1999). The selfregulatory student's engagement in metacognitive activities engenders the optimal adoption of strategies to the requirements of the task. For this all study strategies may be deployed. 
Various authors have found that the use of study strategies was positively related to exam scores (Pintrich and DeGroot 1990; Elliot et al. 1999; Wolters 2004).

\section{Achievement goals and strategy use}

Research on, and programs that teach, study strategies (e.g. Entwistle and McCune 2004; Garcia and Pintrich 1996; Weinstein and Mayer 1986) provide the taxonomy and the means for assessing these activities, which include cognitive and metacognitive strategies and resource management strategies. Cognitive strategies are classified into surface cognitive strategies and deep cognitive strategies. Surface cognitive strategies refer to rehearsal, involving the repetitive rehearsal and rote memorization of information, which helps to encode new information into short-term memory, e.g. reading the course material over and over again. Deep cognitive strategies, pertaining to elaboration, organization and critical thinking, involve challenging the veracity of information encountered and attempting to integrate new information with prior knowledge and experience, which facilitates long-term retention of the target information (e.g. making an outline of important concepts). Metacognitive strategies, basically consisting of planning (e.g. goal setting in order to direct the study activities for a course), monitoring and regulating, help students control and execute their learning process (e.g. changing the way to read if course materials are difficult to understand). Resource management includes student's regulatory strategies for controlling other resources besides their cognition. These strategies manage one's time (e.g. making a study schedule and stick to it) and study environment (e.g. choosing the right place to concentrate on course work) and focus on the use of others in learning: peer learning (e.g. using a study group or friends to help with learning) and help seeking (e.g. seeking help from peers and instructors when needed).

According to Alexander's (2003) Model of Domain Learning the nature of developing expertise in academic domains progress from acclimation to competency and proficiency. At the initial acclimation stage students have limited and fragmented knowledge and lack a cohesive and well-integrated body of domain knowledge. Given this state of knowledge students frequently use surface cognitive strategies to make sense of the course material. The transformation into competency is marked by quantitative and qualitative changes in knowledge and strategy use which are linked to increases in personal interest. Competent learners demonstrate a more integrated body of domain knowledge, As the problems in the domain become more familiar learners delve into such tasks by applying a mix of surface cognitive and deep cognitive strategies.

Studies examining the link between performance goals and the use of deep cognitive strategies in college students have yielded rather clear results: performance goals are consistently unrelated to student's use of deep cognitive strategies. However, Elliot et al. (1999), Pintrich (2000) and Wolters (2004) noticed that most of the research on the relationship of performance goals and study strategies did not distinguish between approach and avoidance versions of performance goals. Wolters (2004) distinguished between approach and avoidance versions of performance goals and found that performanceapproach goals were positively related to the use of deep cognitive strategies.

Surface processing involves the repetitive rehearsal and rote memorization of information. It is assumed by theorists (e.g. Elliot et al. 1999) that surface processing is integral to the development of a comprehensive knowledge base. Academic exams often test the memorization of information provided in a course. Surface cognitive strategies might be necessary for examinations such as multiple-choice tests or exam questions that 
do not test for deep understanding or integration of the material. Thus, approach and avoidance performance-goals could have positive relationships with students' use of surface cognitive strategies. Several studies reported that performance goals are positively related to students' use of surface cognitive strategies (Elliot et al. 1999). Furthermore, Elliot et al. (1999, study 1) found that performance-avoidance goals were positively related to the use of surface strategies. In addition, Dupeyrat and Martiné (2005) showed that performance-approach goals had a positive relationship with student's use of surface cognitive strategies

Wolters (2004) concluded that studies involving college students that did not separate approach and avoidance goals failed to find any clear evidence linking students' endorsement of performance goals and their use of metacognitive strategies. In addition, Somuncuoglu and Yildirim (2001) found that an ego-social goal orientation-comparable with performance-approach goals - was not related to the use of metacognitive strategies. The research of Wolters (2004) showed that performance-approach goals were positively related to the use of metacognitive strategies.

Few data are available regarding the link between achievement goals and resource management strategies. Resource management strategies consist of time and study management strategies, and of peer learning and help seeking from peers and instructors. Performance-approach goals focus on positive outcomes, which might impel efforts to devise a structured study regimen and seek instrumental help to gain assistance sufficient to achieve independently.

The research of Suárez Reveiro et al. (2001) showed that a work-avoidance orientationcomparable with performance-avoidance goals-was negatively related to time and study management. Elliot et al. (1999) hypothesized that the pursuit of performance-avoidance goals would result in disorganization. They found that disorganization, which is the opposite of time and study management, was positively related to the pursuit of performance-avoidance goals. Thus, the weak adoption of performance-avoidance goals would be related to the strong use of time and study management.

\section{Overview of the present research}

Starting from a number of core concepts in the theoretical models of self-regulated learning and based on the results of empirical research, the relations between achievement goals, metacognition, strategy use and achievement were put into a complex causal model that was tested. Specifically, the following relationships were posited. (1) Mastery and performance-approach goals would have a positive relationship. Further, performanceapproach and -avoidance goals would have a positive relationship, and performanceavoidance goals would be negatively related to mastery goals. (2) Mastery goals would be positively related to metacognition, which in turn would positively affect students' use of deep cognitive, metacognitive, surface cognitive and resource management strategies. (3) Performance-avoidance goals would have a negative relationship with metacognition. (4) Performance-approach and -avoidance goals would have positive relationships with students' use of surface cognitive strategies. (5) Performance-approach goals would have a positive relationship, and performance-avoidance goals would have a negative relationship with students' use of resource management strategies. (6) The use of study strategies is expected to predict exam scores.

The hypothesized relationships represent the processes in the effective self-regulated learner. It was assumed that high effort expenditure is characteristic of effective selfregulated learners. We distinguished effective and less effective self-regulated learners 
on the basis of their effort expenditure, and also tested the model for less effective self-regulators.

An important question is the extent to which the patterns in the model are independent of intellectual ability. Veenman (e.g. Veenman and Beishuizen 2004) repeatedly observed that the metacognitive regulation of novices - academic students - was positively related to their intellectual ability. Therefore, the hypothesized relationships in the model were tested with controlling for intellectual ability. Brew (2002) studied first-year university students of above-average ability and found gender differences in metacognitive experiences. Albard and Lipschultz (1998) and Zimmerman and Martinez-Pons (1990) found gender and age differences in the use of learning strategies of high-achievers and gifted children. Therefore, we also controlled for gender and age.

\section{Method}

Participants and procedure

First-year psychology students ( $N=952 ; 652$ female and 300 male) cooperated in this study, participating in a number of collective test sessions within the framework of study obligations. These students were also enrolled in the course Introduction to Psychology, which took place in the first semester. The mean age was 21 years $(\mathrm{SD}=4.3)$. More than a week before the exam, participants answered questions regarding effort regulation, achievement goals, engagement in metacognitive activities, and study strategies. The metacognitive activities and the intellectual ability of all participants were assessed during collective test sessions that were different from the sessions in which the other questions were pose.

\section{Variables}

Effort regulation The Motivated Strategies for Learning Questionnaire (MSLQ) devised by Pintrich et al. (1991) includes four items that measure effort regulation. The items that directly measured effort expenditure: 'I work hard to do well in the Introduction to Psychology class even if I don't like what I am doing.' and 'Even when course materials are dull and uninteresting, I manage to keep working until I finish' were significantly correlated, $r=.40$. The items that had to be reversed focus on the opposite of effort expenditure ('I often feel lazy or bored when I study for the Introduction to Psychology class that I quit before I finished what I planned to do.' and 'When course work is difficult I give up or only study the easy parts.') and were not related to the items that focus on effort expenditure. Participants indicated their response to each item on a 1 (not at all true of me) to 7 (very true of me) scale. The mean for the two items that focus on effort expenditure was 4.4 , which is above the midpoint of the 7 -point scale. The median was 4.5 , which indicates that students who had a score above the median answered that effort expenditure is true of them. We considered students with positive responses $(>4)$ to the effort regulation items as effective self-regulated learners and students with non-positive responses $(\leq 4)$ as less effective self-regulated learners.

Achievement goals The achievement goals questionnaire devised by Elliot and Church (1997) was used to assess participants' achievement goals in the course Introduction to Psychology. Six of these questions were related to mastery goals, for example: 'I want to 
learn as much as possible from my Introduction to Psychology classes.' Six were related to performance-approach goals, for example, 'It is important for me to do better than other students in my Introduction to Psychology classes.' Another six were posed to measure performance-avoidance goals, for example, 'I worry about the possibility of getting bad grades in my Introduction to Psychology classes.' In answering, participants indicated their response to each item on a 1 (not at all true of me) to 7 (very true of me) scale. Cronbach's alpha for the six items representing mastery goals was .77 , for the six items representing performance-approach goals alpha was .79, and for the six items measuring performanceavoidance goals it was .85. For the analyses the sum scores were used for each scale.

Metacognition The Awareness of Independent Learning Inventory (AILI) devised by Elshout-Mohr et al. (2004) was constructed for use in higher education. AILI has been shown to be a reliable and valid measure of metacognition related to academic learning tasks. A generalization study indicated that the findings could be generalized to a broader range of metacognitive components and topics of concern than were actually included in the questionnaire. A decision-study indicated that an abbreviated version of AILI would not lead to a serious loss in generalizability (Elshout-Mohr et al. 2004; Meijer et al. 2003, 2006). We used the shortened version of the AILI, which consists of 45 items (half of the items are presented in reversed format) that measure knowledge of cognition (knowledge about persons, strategies and study tasks), regulation of cognition (planning, monitoring and evaluation) and responsiveness (representing metacognitive experience). An example of a knowledge of cognition item is: 'When students find it difficult to gain insight into the material to be studied, I know ways to solve this.' An example of a regulation of cognition item is: "When I start with a text I first ask myself what I will need to do in order to study the text thoroughly.' An example of responsiveness is: 'I sometimes get a sudden feeling that my method of work doesn't suit the assignment.' Participants indicated their response to each item on a 1 (not at all true of me) to 7 (very true of me) scale. The correlations between the scales that represent knowledge of cognition, regulation of cognition and metacognitive responsiveness were larger than .40. Cronbach's alpha for the 45 items was .88 . For the analyses the sum scores were used.

Study strategies The MSLQ devised by Pintrich and Garcia (1991) was used to assess the student's study strategies. The student was requested to consider the strategies used by him or her in relation to the course Introduction to Psychology. Participants indicated their response to each item on a 1 (not at all true of me) to 7 (very true of me) scale. Fifteen items were employed to measure metacognitive strategies, for example, 'I ask myself questions to make sure that I understand the material I have been studying in this class'. Cronbach's alpha for these 15 items was .75. Fifteen items were used to measure deep cognitive strategies, representing elaboration, organization and critical thinking. For example, 'When reading for this course, I try to relate the material to what I already know.' Cronbach's alpha for these items was .80. Surface cognitive strategies were measured with four items representing rehearsal. For example, 'When I study for this course, I practice saying the material to myself over and over again'. Cronbach's alpha was .68. The scale for resource management strategies consists of 15 items, for example, 'I make good use of my study time for this course'. Cronbach's alpha was .76. For the analyses the sum scores were used for each of the study strategy scales.

Achievement The scores of the exam for the introductory psychology course were used to measure achievement. One half of the test consisted of essay questions, the other half of 
multiple-choice questions. This exam was taken more than a week after students completed the questionnaire. The scores were obtained from the study administration.

Intellectual ability We controlled for intellectual ability with tests representing components of Guilford's structure of intellect model. Six tests were used-Verbal Analogies, Hidden Figures, Vocabulary Test, Linear Syllogism, Number Series, and Number Speed-for five primary factors: Induction (I), Quantitative reasoning (RQ), Verbal Comprehension (V), Flexibility of Closure (CF), Fluid Intelligence (Gf) of Crystallized Intelligence (Gc), as shown in Carroll's reanalysis of factor analytic studies (Carroll 1993, pp. 791-795). The unweighted sum of these test scores can be regarded as an IQ equivalent (see also Veenman and Beishuizen 2004).

\section{Statistical analysis}

In order to investigate the relationships between the research variables, we applied structural equation modeling (Bollen 1989), fitting the model to the data of two groups: a group of effective self-regulators, and a group of less effective self-regulators. Background variables sex, age, and intellectual ability were used as control variables. The maximum likelihood estimation method yields estimates of regression coefficients, residual variances and covariances, as well as a chi-square (CHISQ) measure of overall goodness of fit and a root mean square error of approximation (RMSEA). The CHISQ test is a measure of exact fit. A significant chi-square value $(a l p h a=0.05)$ indicates that the model does not fit the data. The RMSEA is a measure of approximate fit. RMSEA values lower than 0.08 indicate satisfactory fit, and values lower than 0.05 indicate close fit (Browne and Cudeck 1992). If necessary, standardized discrepancies were used as a guidance to modify the model. The analyses were conducted with the computer program LISREL (Jöreskog and Sörbom 1996).

\section{Results}

Eight hundred and four students (31\% men, 69\% women) were available for statistical analysis (148 students who did not take the exam, were not included in the analyses). Students with high effort investment represented effective self-regulated learners and students with low effort investment represented less effective self-regulators: 421 students could be characterized as 'effective self-regulators' ( $25 \%$ men, $75 \%$ women), whereas the remaining 383 students were characterized as 'less effective self-regulators' (39\% men, $61 \%$ women). Apparently, women are more likely to be characterized as effective selfregulated learners than men $(p<0.001$ in chi-square test). Table 1 gives descriptive statistics for each of these two groups. It appeared that effective self-regulators were significantly younger, earned significantly higher exam scores, had significant higher achievement goals, scored significantly higher on metacognition and on all study strategies. However, the mean intellectual ability of the two groups was the same.

The fit of the observed variance-covariance matrices of the two groups to Model 1 was poor: $\mathrm{CHISQ}=58.0(d f=13, p<0.001)$ and $\mathrm{RMSEA}=0.095(90 \% \mathrm{CI}=[0.071,0.121])$ for the effective self-regulators and CHISQ $=70.2(d f=13, p<0.001)$ and RMSEA $=0.102(90 \%$ CI $[0.080,0.126])$ for the less effective self-regulators. Inspection of modification indices and standardized residuals showed that the observed covariances between achievement goals and study strategies could not sufficiently be explained through the expected indirect 
Table 1 Descriptive statistics of effective and less effective self-regulators

\begin{tabular}{|c|c|c|c|c|c|}
\hline & \multicolumn{2}{|c|}{$\begin{array}{l}\text { Effective self-regulators } \\
(N=421)\end{array}$} & \multicolumn{2}{|c|}{$\begin{array}{l}\text { Less effective self-regulators } \\
(N=383)\end{array}$} & \multirow[b]{2}{*}{ Probability* } \\
\hline & $M$ & SD & $M$ & $\mathrm{SD}$ & \\
\hline Age & 20.53 & 3.47 & 21.31 & 5.60 & 0.017 \\
\hline Intellectual ability & 0.02 & 0.63 & -0.03 & 0.65 & 0.279 \\
\hline Mastery goals & 5.13 & 0.55 & 4.82 & 0.68 & 0.000 \\
\hline Performance-approach goals & 3.25 & 0.88 & 3.04 & 0.91 & 0.001 \\
\hline Performance-avoidance goals & 3.04 & 1.04 & 2.84 & 1.03 & 0.007 \\
\hline Metacognition & 4.59 & 0.61 & 4.38 & 0.63 & 0.000 \\
\hline Metacognitive strategies & 4.94 & 0.62 & 4.51 & 0.76 & 0.000 \\
\hline Deep cognitive strategies & 4.50 & 0.73 & 4.21 & 0.84 & 0.000 \\
\hline Surface cognitive strategies & 4.32 & 1.09 & 3.68 & 1.18 & 0.000 \\
\hline Resource management & 4.28 & 0.73 & 3.80 & 0.73 & 0.000 \\
\hline Exam scores & 27.75 & 6.98 & 24.92 & 7.83 & 0.000 \\
\hline
\end{tabular}

Note: *probability associated with $t$-test

effects. Step by step modification of Model 1 based on the results for the effective selfregulators, adding the direct effects of achievement goals on study strategies where necessary, yielded Model 2. The fit of Model 2 was close: CHISQ $=9.68(d f=9, p=0.377)$ and RMSEA $=0.013(90 \%$ CI $[0.000,0.058])$. Model 2 is shown in Fig. 1. Estimates of all Model 2 regression coefficients (in standardized common metric) are given in Table 2. Step
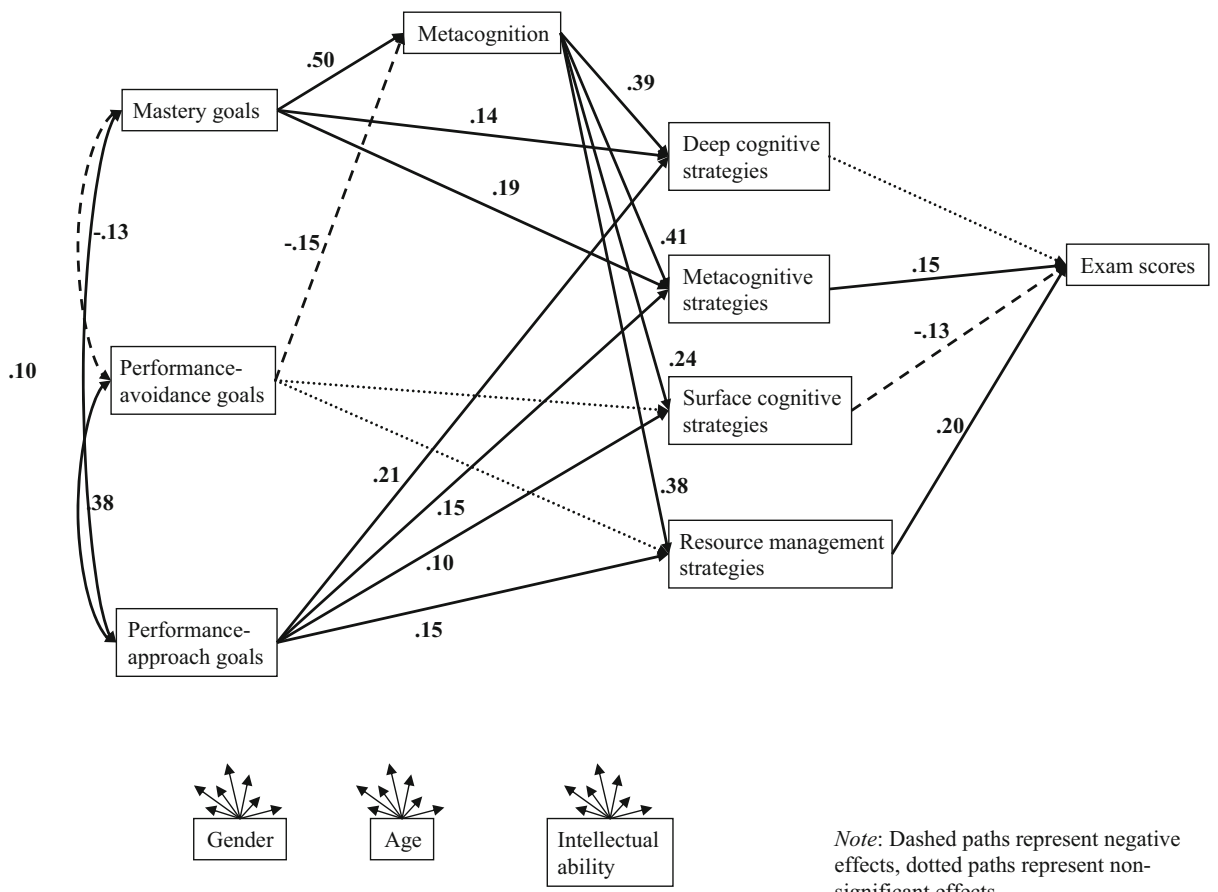

Note: Dashed paths represent negative effects, dotted paths represent nonsignificant effects.

Fig. 1 Observed relationships of achievement goals, metacognition, study strategies and achievement for effective self-regulators 


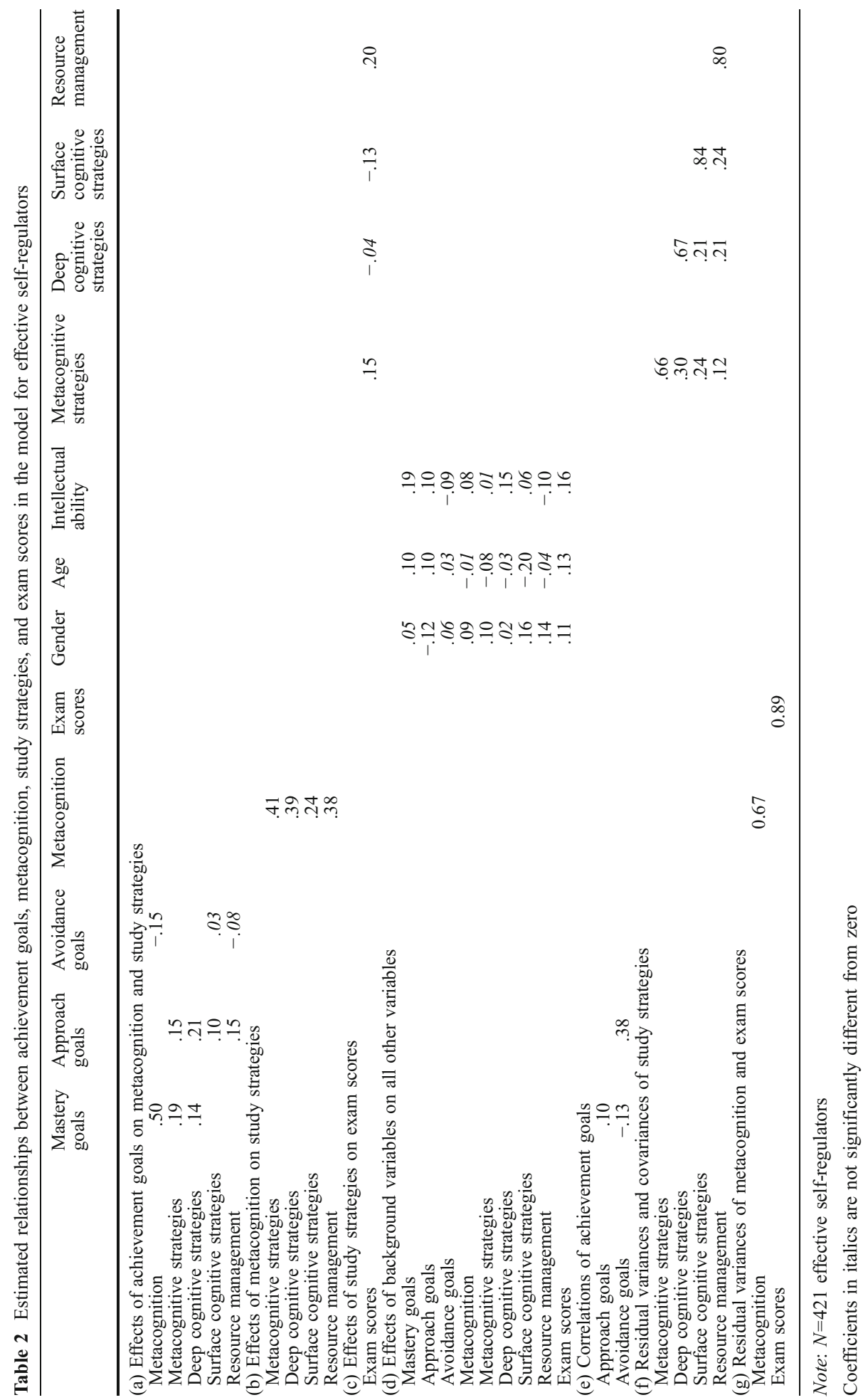


by step modification of Model 1 based on the results for less effective self-regulators, adding the direct effects, where necessary yielded Model 3. The fit of Model 3 was close: $\mathrm{CHISQ}=8.98(d f=7, p=0.254)$ and RMSEA $=0.027(90 \%$ CI $[0.000,0.072])$. Model 3 is shown in Fig. 2. Estimates of all Model 3 regression coefficients (in standardized common metric) are given in Table 3. Tables 2 and 3 have seven parts: (a) effects of achievement goals on metacognition and study strategies, (b) effects of metacognition on study strategies, (c) effects of metacognition and study strategies on exam scores, (d) effects of background variables on all other variables, (e) correlations between achievement goals, (f) residual variances and covariances of study strategies, and $(\mathrm{g})$ residual variances of metacognition and exam scores. As all coefficients are standardized (in common metric), values of $0.1,0.3$, and 0.5 can be considered 'small', 'medium', and 'large'.

Figure 1 and Table 2 show, as expected, that in the case of effective self-regulatory students mastery goals had a small negative relationship with performance-avoidance goals. Consistent with expectation mastery goals had a large positive and performance-avoidance goals had a small negative effect on metacognition and through metacognition on the use of each of the four study strategies. Metacognition had a medium-sized effect on the use of metacognitive, deep cognitive and resource management strategies, and a small effect on the use of surface cognitive strategies. Consistent with expectation, performance-approach goals were directly related to the use of surface cognitive strategies and resource management strategies. Metacognitive strategies and resource management strategies had positive effects on exam scores. Unexpectedly, mastery and performance-approach goals were positively related to the use of deep cognitive and metacognitive strategies, while performance-avoidance goals were not related to the use of surface cognitive strategies and
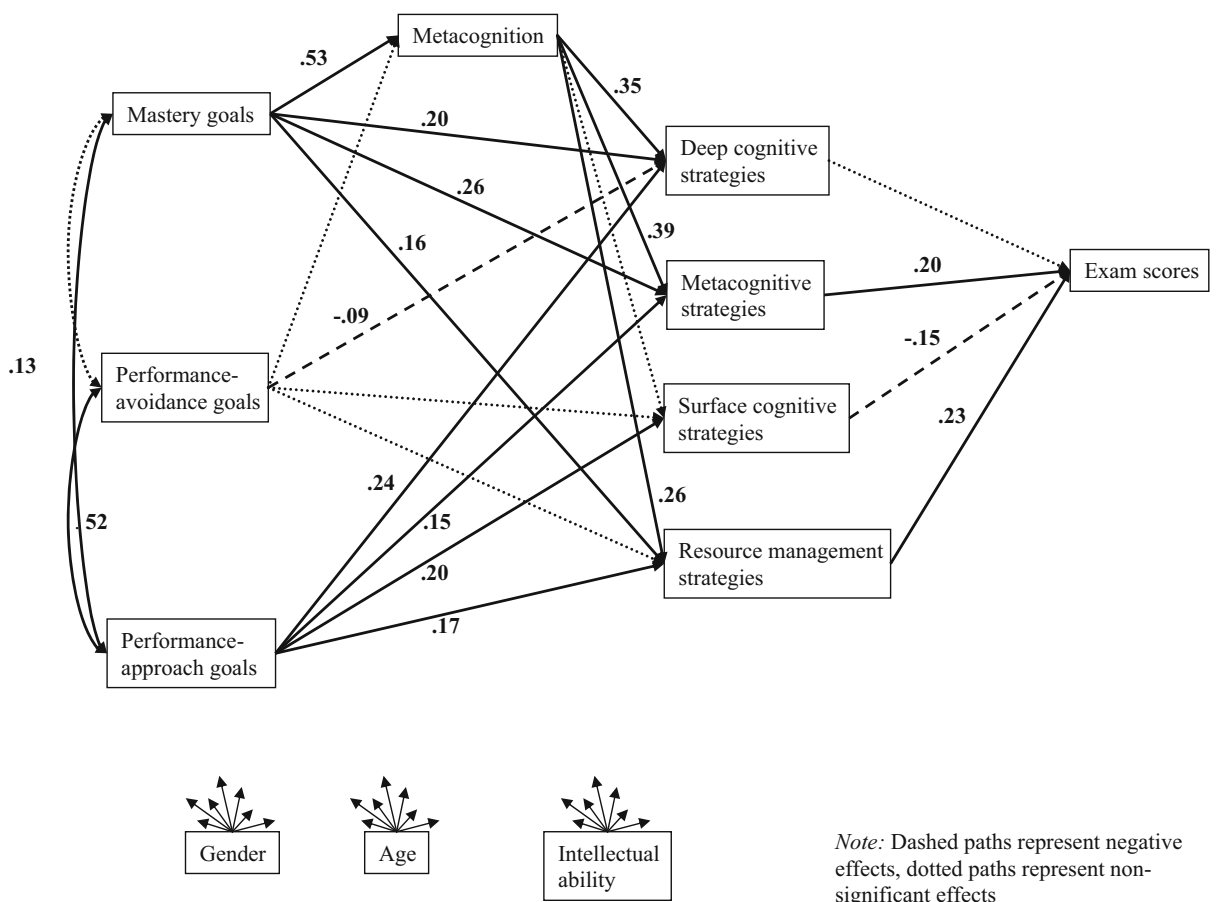

Note: Dashed paths represent negative effects, dotted paths represent nonsignificant effects

Fig. 2 Observed relationships of achievement goals, metacognition, study strategies and achievement for less effective self-regulators 


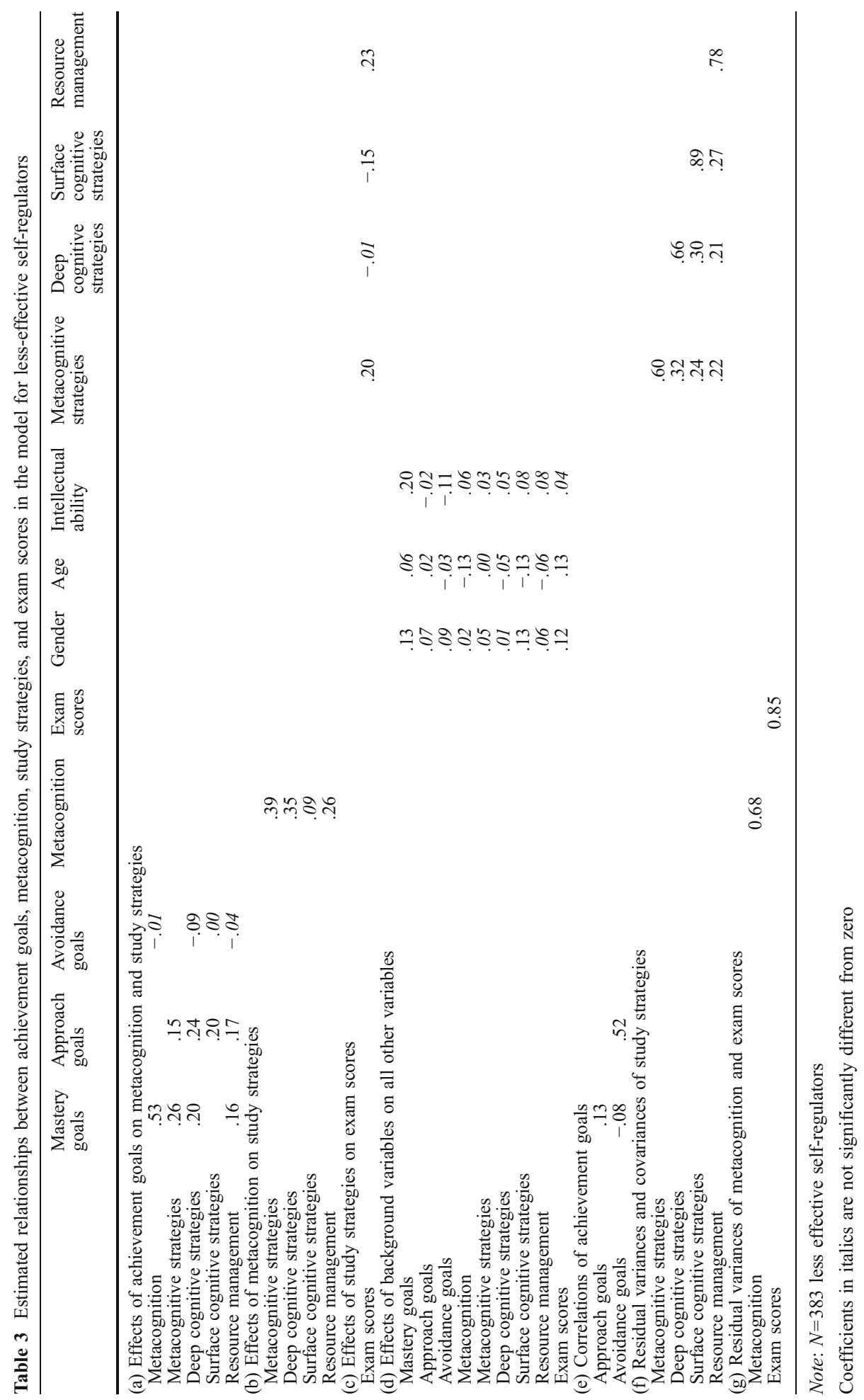


resource management strategies. Further, the use of deep cognitive strategies was unrelated to exam scores and the use of surface strategies had a small negative effect on exam scores.

Table 2 also gives correlations and residual covariances for the effective self-regulators. As expected, mastery goals and performance-approach goals had a (small) positive relationship. Performance approach goals had a medium positive relationship with performance-avoidance goals. Performance-avoidance goals had a small negative relationship with mastery goals. The residual covariances show that not all observed covariances are fully explained by the regression coefficients discussed above (there are positive relationships between the four study strategies).

The results for the less effective self-regulators in Fig. 2 and Table 3 show that a number of paths for less effective self-regulators are the same as those for effective self-regulators. The residual covariances also reveal that there are positive relationships between the four study strategies. There are six relationships in this model that differ from those in the model of effective self-regulators. Mastery and performance-approach goals had a large positive relationship, whereas mastery goals and performance-avoidance goals were unrelated. Further, the pursuit of performance-avoidance goals was unrelated to metacognition. Moreover, metacognition was unrelated to the use of surface cognitive strategies. Further, there occurred two additional effects: a negative effect of avoidance goals on deep processing and a positive effect of mastery goals on resource management.

\section{Discussion}

Our starting point was that students who invest more effort in the task would show a more active engagement in the process of learning and self-regulation than students who invested less effort. The results showed that effort investment was positively related to the pursuit of the three achievement goals, metacognition, and the use of each of the four study strategies. Thus, students who invested more effort showed a more active engagement in the process of learning and self-regulation than students who invested less effort. This more active engagement in learning and self-regulation resulted in higher exam scores.

The model that maps out the pattern of interrelationships between achievement goals, metacognition, study strategies and academic achievement for effective self-regulatory learners did not have a good fit. Step by step modification adding direct effects of performance-approach and mastery goals on deep cognitive and metacognitive strategies yielded the model depicted in Fig. 1. The same procedure resulted in the model for lesseffective learners shown in Fig. 2. Our predictions concerning the effects of performance goals were based on research that did not distinguish between approach and avoidance versions of performance goals. This research showed that performance goals were unrelated to the use of deep cognitive and metacognitive strategies. We distinguished between approach and avoidance versions of performance goals and found that performanceapproach goals predicted the use of deep cognitive and metacognitive strategies, whereas performance-avoidance goals were not related to the use of these strategies. Our predictions concerning the effects of mastery goals were based on empirical evidence that demonstrated that mastery goals affected the engagement in metacognitive activities. The direct effects of mastery goals on the use of deep cognitive and metacognitive strategies that were added to both models confirm the results of previous studies that have demonstrated that mastery goals are positive predictors of the use of deep cognitive and metacognitive strategies (Wolters 2004). 
The results also showed that mastery goals had a small positive relationship with performance-approach goals. This relationship indicates that striving to obtain high grades is not necessary inconsistent with trying to attain mastery, but can co-occur naturally. Mastery goals focus the learner on learning and understanding, but may also tend to lead the learner toward interesting material that is irrelevant to the exam. The simultaneous pursuit of performance approach-goals, which focus on achieving high grades, may prevent learners to dwell on irrelevant material and get disorganized.

We also found that performance-approach and -avoidance goals were positively related. In the case of effective self-regulators performance-approach goals had a medium positive relationship with avoidance goals, in the case of less effective self-regulating learners these goals had a large positive relationship. The research of Elliot and Church (1997) demonstrated that performance-approach and -avoidance goals were positively related to fear of failure. Thus, when students want to earn better grades than others, they also worry about the possibility of getting bad grades, which is especially the case for less effective self-regulators.

\section{Effective self-regulatory students}

Figure 1 shows two pathways. Consistent with expectation, in the first pathway mastery goals had a large positive and performance-avoidance goals had a small negative effect on metacognition and through metacognition on the use of each of the four study strategies Moreover, three of these strategies contributed to exam scores. The pathway from mastery goals to metacognition indicates that students who try to attain task mastery are highly engaged in metacognitive activities. They have awareness of their personal resources in relation to the demands of the task, along with the knowledge of how to regulate their engagement in the task to optimize outcomes.

Schraw et al. (1995) found that students who strongly adopt mastery goals reported more metacognitive knowledge than students with less strong mastery goals. Ford et al. (1998) and Schmidt and Ford (2003) reported that a learning orientation predicted metacognitive regulation. Our results extend these results, because they showed that mastery goals affected the three components of metacognition: metacognitive knowledge, regulation and experience.

As expected, mastery goals had a small negative relation with performance-avoidance goals, which suggest that a weak negative possible self - represented by a performance-avoidance goal - is related to a strong positive possible self - represented by a mastery goal. Moreover, performance-avoidance goals had a small negative effect on metacognition. Consistent with the theory of possible selves (Markus and Ruvolo 1989; Oyserman and Markus 1990) this result indicates that a weak negative possible self may have motivated the self-regulatory student to avoid the feared state by active engagement in metacognitive activities.

Metacognition had medium-sized effects on the use of metacognitive, deep cognitive and resource management strategies, and a small effect on the use of surface cognitive strategies. This supports the notion that students' knowledge of cognition, knowledge of how to regulate their cognitive engagement in the task and metacognitive experience contribute to the selection and use of study strategies.

These results are in line with the findings of Sperling et al. (2004) who measured knowledge of cognition and regulation of cognition by the MAI. The participants in the study of Sperling et al. were first-year students from the USA. We measured knowledge of cognition, regulation of cognition and metacognitive experience by the AILI. Our participants were first-year students from the Netherlands. In spite of these differences 
both studies found a positive relationship between the engagement in metacognitive activities and students' use of all study strategies, which suggests that this finding may be generalized to novices in different academic settings.

Although the engagement in metacognitive activities had a positive effect on the use of each of the four strategies, only two of these study strategies - metacognitive strategies and resource management strategies-had positive effects on exam scores. The use of these two strategies involves metacognitive self-regulation. Resource management involves time management-scheduling, planning and managing one's study time — which is regarded as a prerequisite of effective studying. Metacognitive strategies involve monitoring, checking and regulating of the cognitive processes during the task performance.

Tiaden et al. (2004) have presented a hierarchical model, which maps out the relationships between the four study strategies. They found that planning, comparable with time management, as a prerequisite of effective studying, affected the use of metacognitive and cognitive strategies. Based on the function of metacognitive strategies, they also assumed and demonstrated that the use of these strategies affected the use of (surface and deep) cognitive strategies. We also found that the four strategies were positively related, which suggests that the relationships between the study strategies proceed according to the hierarchical model of Tiaden et al. (2004). The regulating function of planning and metacognitive strategies could explain the positive effects of resource management strategies and metacognitive strategies on exam scores.

Our results also showed that the use of surface strategies had small negative effect on exam scores. This indicates that the limited use of surface strategies results in higher exam scores, which supports the idea that surface processing is integral to the development of a comprehensive knowledge base (Elliot et al. 1999). When the use of surface cognitive strategies is instigated by metacognitive monitoring and regulation (according to the hierarchical model of Tiaden et al. 2004) this safeguards that the limited use of these strategies is appropriate to the task and the exam.

The results concerning this 'metacognitive pathway' are in line with the mastery goal perspective of Ames (1992). Our results support the conclusion of these authors that a mastery goal promotes high-quality involvement in learning. For the strong pursuit of mastery goals instigated metacognitive awareness and the selection of strategies appropriate to the task, which promoted achievement through the regulatory function of resource management and metacognitive strategies. In addition, our results and those from Suárez Reveiro et al. (2001) suggest that learners who are intrinsically motivated also derive benefit from the extrinsic motivation to avoid being judged negatively.

Further, Fig. 1 shows that self-regulated learners also earned high exam scores through another pathway, a pathway in which both mastery and performance-approach goals are involved. Consistent with expectation, performance-approach goals were directly related to the use of surface cognitive strategies and resource management strategies. Unexpectedly, mastery and performance-approach goals were positively related to the use of deep cognitive and metacognitive strategies. Furthermore, the pursuit of performanceavoidance goals was not related to the use of surface cognitive and resource management strategies.

This pathway does not involve the engagement in metacognitive activities, goes directly from performance-approach goals to each of the four study strategies and from mastery goals to metacognitive and deep cognitive strategies. In this pathway performance-approach goals affected exam scores through the use of three strategies-metacognitive, surface cognitive and resource management strategies - whereas mastery goals had an effect on exam scores through the use of one type of strategy — metacognitive strategies. This means 
that the contribution of performance-approach goals to exam scores is stronger than that of mastery goals.

In this pathway the use of metacognitive strategies (as measured by MSLQ) regulates cognitive processes. It is plausible that the regulation which is instigated by metacognitive awareness (as measured by AILI) is based on more thoughtful and deliberate use of metacognitive knowledge and regulation than the regulation of cognition instigated by metacognitive strategies. An example may clarify this matter. An item from the MSLQ representing the use of metacognitive strategies is: 'I ask myself questions to make sure I understand the material I have been studying in this class.' Afflerbach et al. (2008) mentioned that a beginning student who asks him or herself questions to clarify his or her comprehension of course material performs a deliberate metacognitive act of selfquestioning that serves the student's goal of monitoring and building better comprehension. A comparable item from the AILI is: 'When students find it difficult to gain insight into the material to be studied, I know ways to solve it.' When the task is challenging, the more thoughtful and deliberate use of metacognitive knowledge and regulation may be more helpful to novices to adapt their strategy use to the task requirements.

Entwisle and McCune (2004) assume that there is a logical association between motive and strategy. They suggest that students use a strategic approach: when they want to do well, they need to know what 'counts' and then work hard and systematically to meet those requirements. This could apply to the effective self-regulated learners. Then the question is when the self-regulatory learner makes use of the 'metacognitive pathway' and when of the 'strategy pathway'. It is plausible that a challenging task will instigate the learner to focus on learning and understanding, reflect about ways to get insight in the material, make conscious efforts to work systematically and be sensitive to sudden feelings that insights are beginning to develop. In line with this, Veenman and Beishuizen (2004) demonstrated that students who studied a more difficult text showed more engagement in metacognitive activities than students who studied a less difficult text.

When the task is less challenging or not particularly interesting, the self-regulatory learner could cope with this by focusing on obtaining high grades and only aim at learning and understanding in the service of obtaining high grades. These two pathways allow students to flexibly adapt their goal pursuit and manage their learning, so that they are able to attune their behavior optimally to the task and achieve good results (see also Suárez Reveiro et al. 2001).

The psychology students cooperated in this study in the first semester of the first study year. Thus, they were in the initial acclimation stage of domain expertise (Alexander 2003). Our results showed that the effective regulatory students applied a mix of surface and deep cognitive strategies, signifying a movement away from acclimation and toward competency. This movement toward competency in the initial stage of domain learning may result from the optimal attunement of the use of strategies to the exam requirements. The exam of the course Introduction to Psychology included multiple-choice and essay questions. The multiple-choice questions tested whether students made sense of and memorized the information provided in the course, which require the use of surface cognitive strategies. The essay questions tested for deep understanding and integration of the material, which require deep cognitive processing.

\section{Less-effective self-regulatory students}

Figure 2 depicts the model concerning less-effective self-regulators. We did not formulate expectations about the relationships between the variables for less effective self-regulators. 
It is conspicuous that the observed relationships in Fig. 2 also show a metacognitive and a strategy pathway. Before discussing the relationships that are characteristic of less effective self-regulators, it is relevant to note that less effective self-regulators not only invested less effort, but that they also showed less engagement in the learning process and obtained lower exam scores than effective regulators. They allocated their efforts less to achievement goals, engagement in metacognitive activities and the use of strategies.

Although Fig. 2 also shows a metacognitive and an strategy pathway, there are a number of relationships in this model that differ from those in the model of effective self-regulators, which create a quite different picture of the learning process of the less effective selfregulators. Firstly, in the model of less effective self-regulators mastery goals were unrelated to performance-avoidance goals, and the pursuit of performance-avoidance goals was unrelated to the engagement in metacognitive activities. Thus, the limited pursuit of avoidance goals did not have a stimulating effect on the engagement in metacognitive activities, as was the case for effective self-regulating learners. Moreover, the engagement in metacognitive activities was unrelated to the use of surface cognitive strategies. So metacognitive activities did not affect the selection or use of surface processing, and did not contribute to exam scores through surface processing. This small difference might have a substantial effect, since surface processing is relevant for obtaining good exam scores, and is negatively related to exam scores. Thus, in the metacognitive pathway the limited use of surface cognitive strategies relevant for earning good results cannot be effectuated. Together these processes might have impaired the effectiveness of the metacognitive pathway.

In the strategic pathway there occurred two additional effects - of performanceavoidance goals on deep processing and of mastery goals on resource managementwhich enhanced the relative strength of this pathway.

In this pathway the pursuit of performance-avoidance goals had a negative effect on the use of deep cognitive processes. This extra effect influences the processes in the strategy pathway. There were three achievement goals that contributed to the use of deep processing; together these goals had a large effect on the use of deep cognitive strategies. This effect was larger than the effects of achievement goals on the use of metacognitive, resource management strategies or surface cognitive strategies. As a consequence the use of deep cognitive strategies might have prevailed over the use of metacognitive and resource management strategies that have a regulating function. It is plausible that the use of deep cognitive strategies overruled the use of metacognitive strategies, which regulates and controls deep or surface processing. This suggests that the use of deep cognitive strategies was insufficiently regulated and thus not adapted to the task requirements. Altogether these effects may have contributed to impairment of the relatively strong strategy pathway for less effective self-regulators.

It is relevant to note that the number of significant relationships for effective and less effective learners hardly differs. Thus, it is not the quantity but the quality of the relationships that is relevant. These qualitative differences between effective and less effective self-regulators have an impact on the learning process in such a way that the metacognitive pathway is insufficiently adapted to the exam requirements, and that the strategy pathway prevails over the metacognitive pathway. In the latter pathway the effects of achievement goals on deep cognitive processing overrules the effects of regulating strategies that affect exam scores. Further, it is conspicuous that the (lack of) relationships of performance-avoidance goals with mastery goals, engagement in metacognitive activities and deep processing impair the effectiveness of the metacognitive and strategy pathways for less-effective self-regulators. This evidence supports the conclusion of Barron and 
Harackiewicz (2001) and Harackiewicz et al. (2002) that maladaptive learning patterns are mainly associated with performance-avoidance goals.

Intellectual ability, gender and age

Several studies with first-year psychology students performing learning tasks showed that intellectual ability and metacognitive activities were related (Veenman and Beishuizen 2004). For this reason we controlled for intellectual ability. Our results revealed a positive relationship between intellectual ability and metacognitive activities for effective, but not for less effective self-regulators. The intellectual ability of effective self-regulators also had a positive relationship with exam scores, while the intellectual ability of less effective selfregulators was unrelated to their exam scores. These results are in agreement with the 'mixed model' that describes the relation between intellectual ability and metacognition as predictors of novice learning. According to the mixed model metacognition is related to intellectual ability to some extent, but also has a surplus value on top of intellectual ability for the prediction of novice learning (Veenman and Verheij 2003). Our results suggest that the mixed model especially applies to the learning process of effective self-regulators.

We also controlled for gender and age. The results revealed that female effective selfregulators were more engaged in metacognitive activities. Brew (2002) studied first-year students with above-average ability and found that for female students sensitivity to metacognitive experiences and being open to new ideas were highly integrated, whereas for male students sensitivity to metacognitive experiences and being open to new ideas were not necessarily associated. Brew suggested that women's sensitivity to metacognitive experiences and their openness to new ideas are related to women's stronger orientation to their own and other people's feelings and interpersonal relationships. Albard and Lipschultz (1998) and Zimmerman and Martinez-Pons (1990) found that high-achieving and gifted girls in middle and high school reported greater use of resource management and metacognitive strategies. In line with this, we found that female university students who were effective self-regulators made more use of resource management, metacognitive strategies and obtained higher exam scores than male effective self-regulators.

The results also showed that younger students who were effective self-regulators obtained higher exam scores than older effective self-regulators. The older students often worked a number of years before starting with the study of psychology. Many older students find it difficult to devise a structured study regimen and to adequately utilize study strategies. Perhaps this explains that while they used more metacognitive strategies than younger students they obtained lower exam scores.

\section{Limitations}

There are a number of limitations that should be considered when interpreting the present results. First it could be argued that the current sample lacked representativeness, given that the participants were novices in the domain of psychology and the sample was predominantly female. More research is called for before we can know whether the current results generalize to other populations, domains and samples with equal numbers of women and men. A second potential limitation is that the test of introduction to psychology included multiple-choice and essay questions. It is possible that the models of effective and less effective self-regulatory students are specific for this type of exam.

A third potential limitation is related to the operationalization of effort regulation, engagement in metacognitive activities and study strategies based on self-report. It is 
plausible that a survey of actual study investment would have provided more data concerning the actual investment in hours. We interviewed 50 students who participated in the present study and asked their actual study investment in hours. Most students did not remember how many hours they studied for the exam, they reported the number of days (Goudsmit 2007). Perhaps the results support our operationalization of effort, because we asked to what extent they worked hard and kept working. The findings concerning engagement in metacognitive activities and the use of study strategies were also based on student's self-report, thus we cannot be sure that students actually were engaged in all the metacognitive activities that they reported nor that they used all of the reported strategies. Thus, it is advisable in further research to also administer interviews to gather data about student's engagement in metacognitive activities during task performance (Luwel et al. 2003) and use behavioral observation of effort and strategy use based on log data.

\section{Conclusion}

Starting from a number of core concepts in the theoretical models of self-regulated learning, and based on the results of empirical research, the relations between goals, engagement in metacognitive activities, strategy use and achievement were put into a complex causal model that was tested. The results of this study may provide clues for further theoretical development and practical applications. Theorists, such as Boekaerts (1997), Pressley (1995) and Winne (2005), have pointed out that it is important to examine in what respects effective and less-effective self-regulatory students differ. The present study sheds light on qualitative differences between effective and less-effective self-regulatory students. Such data can promote theoretical development concerning less-effective self-regulated learning. More knowledge of the difference between effective en less effective self-regulated learning may enhance the effect of interventions that focus on the development of complicated academic competencies.

Our results indicate that successful self-regulation in the achievement domain may be conditional, such that for some task components mastery goals, weak avoidance goals, and engagement in metacognitive activities are optimal, whereas for other task components mastery goals, performance-approach goals, and the direct use of metacognitive strategies are more effective (e.g. Elliot et al. 1999). This implies that interventions should not only include a focus on achievement goals, engagement in metacognitive activities or strategy use, but also a consideration of when different self-regulatory profiles are to be recommended.

Open Access This article is distributed under the terms of the Creative Commons Attribution Noncommercial License which permits any noncommercial use, distribution, and reproduction in any medium, provided the original author(s) and source are credited.

\section{References}

Afflerbach, P., Pearson, P. D., \& Paris, S. G. (2008). Clarifying differences between reading skills and reading strategies. The Reading Teacher, 61, 364-373.

Albard, K. E., \& Lipschultz, R. E. (1998). Self-regulated learning in high-achieving students: relations to advanced reasoning, achievement goals, and gender. Journal of Educational Psychology, 90, 94-100. 
Alexander, P. A. (2003). The development of expertise: the journey from acclimation to proficiency. Educational Researcher, 32, 10-14.

Ames, C. (1992). Classrooms: goals, structures and student motivation. Journal of Educational Psychology, $84,261-271$.

Barron, K., \& Harackiewicz, J. (2001). Achievement goals and optimal motivation: testing multiple goal models. Journal of Personality and Social Psychology, 80, 706-722.

Boekaerts, M. (1997). Self-regulated learning: a new concept embraced by researchers, policy makers, educators, teachers and students. Learning and Instruction, 7, 161-186.

Boekaerts, M., \& Corno, L. (2005). Self-regulation in the classroom: a perspective on assessment and intervention. Applied Psychology: An International Review, 54, 199-231.

Bollen, K. A. (1989). Structural equations with latent variables. New York: Wiley.

Brew, C. R. (2002). Kolb's learning style instrument: sensitive to gender. Educational and Psychological Measurement, 62, 373-390.

Brown, A. (1987). Metacognition, executive control, self-regulation and other more mysterious mechanisms. In F. Weinert, \& R. Kluwer (Eds.), Metacognition, motivation and understanding (pp. 65-116). Hillsdale: Erlbaum.

Browne, M. W., \& Cudeck, R. (1992). Alternative ways of assessing model fit. Sociological Methods \& Research, 21, 230-258.

Carroll, J. B. (1993). Human cognitive abilities: a survey of factor analytic studies. Cambridge: Cambridge University Press.

Covington, M. V. (1983). Motivated cognition. In S. Paris, G. Olson, \& H. Stevenson (Eds.), Learning and motivation in the classroom (pp. 139-164). San Diego: Academic.

Covington, M. V. (1985). Strategic thinking and the fear of failure. In J. W. Segal, S. F. Chipman, \& R. Glaser (Eds.), Thinking and learning skills (pp. 398-416). Hillsdale: Erlbaum.

Cross, D. R., \& Paris, S. G. (1988). Developmental an instructional analysis of children's metacognition and reading comprehension. Journal of Educational Psychology, 80, 131-142.

Dupeyrat, C., \& Martiné, C. (2005). Implicit theories of intelligence, goal orientation, cognitive engagement, and achievement: a test of Dweck's model with returning to school adults. Contemporary Educational Psychology, 30, 43-59.

Dweck, C., \& Leggett, E. (1998). A social-cognitive approach to motivation and personality. Psychological Review, 95, 256-273.

Efklides, A., \& Petkaki, C. (2002). Effects of mood on students' metacognitive experiences. Learning and Instruction, 15, 415-431.

Elliot, A. J. (1997). Achievement goals and approach-avoidance motivation. Educational Psychologist, 34, $169-189$.

Elliot, A. J., \& Church, M. A. (1997). A hierarchical model of approach and avoidance achievement motivation. Journal of Personality and Social Psychology, 72, 218-232.

Elliot, A. J., McGregor, H. A., \& Gable, S. (1999). Achievement goals, study strategies, and exam performance: a mediational analysis. Journal of Educational Psychology, 91, 549-563.

Elshout-Mohr, M. (1992). Metacognitie van lerenden in onderwijsprocessen. (Metacognition of learners in teaching-learning processes). Tijdschrift voor Onderwijsresearch, 17, 273-289.

Elshout-Mohr, M., Meijer, J., van Daalen-Kapteijns, M. M., \& Meeus, W. (2004). Joint Research into the AILI (Awareness of Independent Learning Inventory). Paper presented at the first EARLI-SIG on Metacognition. Program and abstract book, p.18. Amsterdam: University of Amsterdam.

Entwisle, N., \& McCune, V. (2004). The conceptual bases of study strategy inventories. Educational Psychology Review, 16, 325-345.

Flavell, J. H. (1979). Metacognition and cognitive monitoring: a new area of cognitive-developmental inquiry. American Psychologist, 34, 906-911.

Flavell, J. H., \& Wellman, H. M. (1977). Metamemory. In R. V. Kail, \& J. W. Hagen (Eds.), Perspectives on the development of memory and cognition (pp. 3-33). Hillsdale: Erlbaum.

Ford, J. K., Smith, E. M., Weissbein, D. A., Gully, S. M., \& Salas, E. (1998). Relationships of goal orientation, metacognitive activity and practice strategies with learning outcomes and transfer. Journal of Applied Psychology, 83, 218-233.

Garcia, T., \& Pintrich, P. R. (1996). Assessing students' motivation and learning strategies in the classroom context: The Motivated Strategies for Learning Questionnaire. In M. Birenbaum, \& F. J. R. C. Dochy (Eds.), Alternatives in assessment of achievements, learning processes and prior knowledge (pp. 319339). New York: Kluwer/Plenum.

Goudsmit, E. (2007). Interviews over inzet en strategiegebruik bij Inleiding 2. (Interviews concerning effort investment and strategy use for Introduction to Psychology) Master thesis. Department of Psychology, University of Amsterdam. 
Harackiewicz, J. M., Barron, K. E., \& Elliot, A. J. (1998). Rethinking achievement goals: when are they adaptive for college students and why. Educational Psychologist, 33, 1-21.

Harakiewicz, J., Barron, K., Pintrich, P., Elliot, A., \& Thrash, T. (2002). Revision of achievement goal theory: necessary and illuminating. Journal of Educational Psychology, 94, 638-645.

Jacobs, J. E., \& Paris, S. G. (1987). Children's metacognition about reading: issues in definition, measurement and instruction. Educational Psychologist, 22, 255-278.

Jöreskog, K. G., \& Sörbom, D. (1996). LISREL 8 user guide (2nd edition). Chicago: Scientific Software International.

Luwel, K., Torbey, J., \& Verschaffel, L. (2003). The relation between metastrategy knowledge, strategy use and task performance: findings and reflections from a numerosity judgment task. European Journal of Psychology of Education, 18, 425-447.

Markus, H., \& Ruvolo, A. (1989). Possible selves: personalized representations of goals. In L. A. Pervin (Ed.), Goal concepts in personality and social psychology (pp. 211-241). Hillsdale: Erlbaum.

McKenzie, K., Gow, K., \& Schweitzer, R. (2004). Exploring first-year academic achievement through structural equation modelling. Higher Education Research and Development, 23, 95-112.

Meijer, J., Elshout-Mohr, M., van Daalen-Kapteijns, M., \& Meeus, W. (2003). A self-report inventory for metacognition related to academic tasks. Paper presented at the 10th EARLI conference on Learning and Instruction. Abstract book, p. 273. Padova: University of Padova.

Meijer, J., Elshout-Mohr, M., van Daalen-Kapteijns, M., Meeus, W., \& Tempelaar, D. (2006). Construction and validation of a questionnaire on metacognition. Paper presented at the second meeting of EARLI Sig 16 on Metacognition. Conference book, p. 18. Cambridge, UK: University of Cambridge.

Midgley, C., Kaplan, A., Middleton, M., Maehr, M., Urdan, T., Anderman, L., et al. (1998). The development and validation of scales assessing students' achievement goal orientations. Contemporary Educational Psychology, 23, 113-131.

Olausen, B. S., \& Bräten, I. (1999). Students' use of strategies for self-regulated learning: cross-cultural perspectives. Scandinavian Journal of Educational Research, 43, 409-431.

Oyserman, D., \& Markus, H. (1990). Possible selves and delinquency. Journal of Personality and Social Psychology, 59, 112-125.

Pintrich, P. R. (2000). The role of goal orientation in self-regulated learning. In M. Boekaerts, P. R. Pintrich, \& M. Zeidner (Eds.), Handbook of self-regulation (pp. 452-494). San Diego: Academic.

Pintrich, P. R. (2004). A conceptual framework for assessing motivation and self-regulated learning in college students. Educational Psychology Review, 16, 385-407.

Pintrich, P. R., \& DeGroot, E. V. (1990). Motivational and self-regulated learning components of classroom academic performance. Journal of Educational Psychology, 82, 33-40.

Pintrich, P. R., \& Garcia, T. (1991). Student goal orientation and self-regulation in the classroom. In M. L. Maehr, \& P. R. Pintrich (Eds.), Advances in motivation and achievement (vol. vol. 10, (pp. 99-141)). Greenwich: JAI.

Pintrich, P. R., Smith, D. A., Garcia, T., \& McKeachie, W. J. (1991). A manual for the use of the Motivated Strategies for Learning Questionnaire (MSLQ). Ann Arbor: University of Michigan, National Centre for Research to Improve Postsecondary Teaching and Learning.

Pressley, M. (1995). More about the development of self-regulation: complex, long-term and thoroughly social. Educational Psychologist, 30, 207-212.

Schmidt, A. M., \& Ford, K. J. (2003). Learning with a learner control-training environment: the interactive effects of goals orientation and metacognitive instruction on learning outcomes. Personnel Psychology, $56,380-405$.

Schraw, G., \& Dennison, R. S. (1994). Assessing metacognitive awareness. Contemporary Educational Psychology, 19, 460-475.

Schraw, G., Horn, C., Thorndike-Christ, T., \& Bruning, R. (1995). Academic goal orientations and student classroom achievement. Contemporary Educational Psychology, 20, 359-368.

Schunk, D. H. (2001). Social cognitive theory and self-regulated learning. In B. J. Zimmerman, \& D. H. Schunk (Eds.), Self-regulated learning and academic achievement: theoretical perspectives (pp. 125151). Mahwah: Erlbaum.

Somuncuoglu, J., \& Yildirim, A. (2001). Relationship between achievement goal orientations and use of learning strategies. Journal of Educational Psychology, 92, 267-277.

Sperling, R. A., Howard, B. C., Staley, R., \& DuBois, N. (2004). Metacognition and self-regulated learning constructs. Educational Research and Evaluation, 10, 117-139.

Suárez Reveiro, J. M., Gonzales Cabanach, R., \& Valle Arias, A. (2001). Multiple-goal pursuit and its relation to cognitive, self-regulatory, and motivational strategies. British Journal of Educational Psychology, 71, 561-572. 
Tiaden, C., Grieder, S., \& Steiner, G. (2004). Metacognition and its relatedness to self-regulated learning. Paper presented at the first EARLI SIG meeting on metacognition. Program and abstract book, p. 29. Amsterdam: University of Amsterdam.

Veenman, M. V. J., \& Beishuizen, J. J. (2004). Intellectual and metacognitive skills of novices while studying texts under conditions of text difficulty and time constraint. Learning and Instruction, 14, 621-640.

Veenman, M. V. J., Van Hout-Wolters, B. H. A. M., \& Afflerbach, P. (2006). Metacognition and learning: conceptual and methodological considerations. Metacognition and Learning, 1, 3-14.

Veenman, M. V. J., \& Verheij, J. (2003). Technical students' metacognitive skills: relating general vs. specific metacognitive skills to study success. Learning and Individual Differences, 13, 259-272.

Weiner, B. (1986). An attributional theory of achievement motivation and emotion. New York: Springer.

Weinstein, C. E., \& Mayer, R. E. (1986). The teaching of learning strategies. In M. Wittrock (Ed.), Handbook of research on teaching (pp. 315-327, 3rd ed.). New York: Macmillan.

Winne, P. H. (1996). A metacognitive view of individual differences in self-regulated learning. Learning and Individual Differences, 8, 327-353.

Winne, P. H. (2001). Self-regulated learning viewed from models of information processing. In B. J. Zimmerman, \& D. H. Schunk (Eds.), Self-regulated learning and academic achievement: theoretical perspectives (pp. 153-189). Mahwah: Erlbaum.

Winne, P. H. (2005). A perspective on state-of-the-art research on self-regulated learning. Instructional Science, 33, 559-565.

Wolters, C. A. (2003). Regulation of motivation: evaluating an underemphasized aspect of self-regulated learning. Educational Psychologist, 38, 189-205.

Wolters, C. A. (2004). Advancing achievement goal theory: using goals structures and goal orientations to predict students' motivation, cognition and achievement. Journal of Educational Psychology, 96, $236-250$

Zimmerman, B. J. (2000). Attaining self-regulation: a social cognitive perspective. In M. Boekaerts, P. R. Pintrich, \& M. Zeidner (Eds.), Handbook of self-regulation (pp. 13-39). San Diego: Academic.

Zimmerman, B. J., \& Kitsantas, A. (2005). The hidden dimension of personal competence: self-regulated learning and practice. In A. J. Elliot, \& C. S. Dweck (Eds.), Handbook of competence and motivation (pp. 509-526). New York: Guilford.

Zimmerman, B. J., \& Martinez-Pons, M. (1990). Student differences in self-regulated learning: relating grade, sex and giftedness to self-efficacy and strategy use. Journal of Educational Psychology, 82, 51-59.

Zimmerman, B. J., \& Schunk, D. H. (2001). Self-regulated learning and academic achievement: theoretical perspectives. Mahwah: Erlbaum. 